\title{
A REPRESENTAÇÃO NO INTERIOR DAS EXPERIÊNCIAS DE PARTICIPAÇÃO
}

Lígia Helena Hahn Lüchmann

Elementos centrais da teoria democrática, as noções de participação e representação vêm demarcando, historicamente, as principais diferenças na confusa - e polissêmica - trajetória da constituição de modelos de democracia ${ }^{1}$. Trata-se de dois conceitos que, por marcarem diferenças significativas nas orientações normativas acerca da melhor forma de governo, tendem a ser dicotomizados nas reflexões e proposições teórico-analíticas, carregando uma disputa de representações e orientações acerca do significado e do papel da política e da democracia em nossas sociedades. Assim, embora referenciados na idéia de participação política, ambos os conceitos registram, com orientações diversas, dois modelos centrais de organização política democrática, quais sejam: o modelo da democracia representativa (R), ancorado na idéia de que as decisões políticas são derivadas das instâncias formadas por representantes escolhidos por sufrágio universal; e o modelo da democracia participativa $(\mathrm{P})$, por sua vez, assentado na idéia de que compete aos cidadãos, no seu conjunto, a definição e autorização das decisões políticas. No primeiro caso, como sabemos, o ponto

${ }^{1}$ Seguindo análise dos modelos de democracia de Held (1987). 
alto da participação política da população ocorre no contexto do processo eleitoral. No segundo caso, busca-se ampliar sobremaneira as responsabilidades políticas, estendendo - em grau e número - os espaços e os sujeitos da deliberação pública.

Neste artigo, pretendo analisar, a partir do incremento de experiências participativas no Brasil neste último par de décadas, as relações entre participação e representação no interior dessas experiências, sugerindo que, muito menos do que oposição, estes instrumentos estabelecem combinações e articulações que desenham um processo de concomitante inovação e reprodução das práticas e orientações político-institucionais.

Será, portanto, o fenômeno da representação no interior da participação (ou das práticas de participação e representação - p\&r) o objeto central de análise neste artigo, ancorado no pressuposto de que as reflexões teóricas sobre estes dois instrumentos de ação política - participação e representação - têm feito predominar um viés dualista, que guarda 140 separações dadas pelos diferentes modelos democráticos; assim, obviamente, participação conforma o eixo analítico das teorias da democracia participativa $(\mathrm{P})$ e representação, da democracia representativa $(\mathrm{R})$.

Para tanto, o artigo está subdividido em quatro seções, sendo as três primeiras reservadas à apresentação de alguns fatores que parecem cooperar significativamente para este dualismo, quais sejam: os quadros de referência analítica que, embora com diferenças e especificidades, tratam, de maneira geral, P e R de forma separada e como formas constitutivas de modelos diferenciados de democracia (primeira parte); a íntima relação entre $\mathrm{P}$ e sociedade civil (segunda parte), e; por último, a incorporação, no plano das práticas institucionais, dos princípios da participação por meio de uma diversidade de regras e critérios que buscam combinar participação e representação (terceira parte).

Com base no acúmulo de avaliações empíricas empreendidas no país, a quarta e última seção visa a refletir acerca dos 
subsídios teórico-analíticos disponíveis, na medida em que estas experiências (p\&r) trazem à tona algumas novidades - e especificidades - que parecem desafiar o referencial analítico disponível acerca da representação política moderna, “cujas potencialidades máximas aparecem particularmente cristalizadas nos limites estruturais do mecanismo eleitoral para garantir a representatividade das instituições da democracia” (Gurza Lavalle, Houtzager, Castello, 2006a: 52).

$\mathrm{O}$ artigo parte do pressuposto, portanto, da necessidade de problematizar a dimensão da representação no interior da participação, procurando, de forma muito preliminar, inserir-se neste debate. Nesse sentido, reconhece algumas iniciativas promissoras para o aprofundamento desta temática, a exemplo do número 67 da Revista Lua Nova, dedicado ao tema sobre $O$ futuro da representação. Embora o foco analítico reproduza uma leitura pautada nas diferenças entre os modelos de $\mathrm{P}$ e R, alguns artigos, ao enfatizarem a importância da participação da sociedade civil para o processo de "reconfiguração e alargamento" da representação política, oferecem importantes contribuições para o debate acerca da representação no interior da participação (p\&r).

Embora não seja objeto de atenção neste espaço, convém apenas destacar as dificuldades de p\&r diante do sistema político ancorado em $\mathrm{R}$, dificuldades estas que tendem a colocar os primeiros em uma relação de subordinação ao segundo ${ }^{2}$.

\footnotetext{
${ }^{2}$ Alguns estudos apontam nesta direção. De acordo com Tatagiba e Teixeira (2006), as experiências participativas no Brasil acabam ficando na periferia do sistema, "afetando pontualmente uma ou outra política setorial, a depender da vontade política dos governos e/ou do poder de pressão da sociedade organizada”. Em análise das experiências de OP no Estado de Santa Catarina, Borba e Lüchmann (2006) avaliam que "a alegada compatibilidade entre democracia participativa e democracia representativa tende a escamotear, no caso das experiências de OP, o fato de que a primeira, sendo um programa de governo, está diretamente subordinada à segunda: seja em função de sua dependência aos princípios e pressupostos do projeto político-governamental; seja em relação às determinantes do processo (e do calendário) eleitoral; seja ainda em relação à lógica dominante - sustentada pelo recorrente apelo à "governabilidade" - da formação das coligações eleitorais".
} 


\section{Participação e teoria democrática}

As experiências participativas no país vêm estimulando o desenvolvimento e a incorporação de novos modelos teóricos de democracia que ampliam os atores e os espaços da política. Democracia participativa e democracia deliberativa têm sido, entre um conjunto mais amplo de proposições e modelos, os principais instrumentos teórico-analíticos de avaliação destas experiências, na medida em que, embora com trajetórias diferenciadas ${ }^{3}$, compartilham um conjunto de críticas ao modelo da democracia representativa, dando primazia ao princípio $\mathrm{P}$ em detrimento de $\mathrm{R}$.

No que diz respeito à democracia participativa, o seu questionamento acerca do caráter instrumental, individualista e competitivo da democracia representativa, mediante a redução da política ao mecanismo eleitoral, está ancorado, e guarda íntima centralidade, na recuperação da articulação entre cidadania e soberania popular por meio da participação dos cidadãos nos processos de discussão e de decisão política (Pateman, 1992; Macpherson, 1978).

Visando ao aprimoramento da democracia representativa liberal, os participacionistas incorporam - ou combinam - pressupostos da democracia direta no interior da democracia representativa, dando ênfase à inclusão dos setores excluídos do debate político e à dimensão pedagógica da política. Para Pateman, (1992), a participação é educativa e promove, por um processo de capacitação e conscientização (individual e coletiva), o desenvolvimento da cidadania, cujo exercício configura-se como requisito central na ruptura com o ciclo de subordinação e de injustiças sociais. Com efeito, a participação conferiria um outro ciclo (virtuoso) ancorado nas relações entre participação cidadã, mudança da consciência política e redução das desigualdades sociais (Macpherson, 1978).

\footnotetext{
${ }^{3}$ Miguel (2005).
} 
Por outro lado, a democracia deliberativa vai dar centralidade à questão da participação com base em uma nova concepção acerca da legitimidade política. Acusando as fragilidades da democracia representativa e a redução da legitimidade do processo decisório ao resultado eleitoral, a democracia deliberativa advoga que a legitimidade das decisões políticas advém de processos de discussão que, orientados pelos princípios da inclusão, do pluralismo, da igualdade participativa, da autonomia e do bem-comum, conferem um reordenamento na lógica de poder tradicional. De acordo com Bohman (2000: 57), "a razão pública é exercida não pelo Estado, mas na esfera pública de cidadãos livres e iguais". A ênfase nas condições de liberdade e igualdade dos sujeitos deliberativos também é encontrada em Cohen (1999: 73), que concebe os resultados como sendo democraticamente legítimos apenas quando objeto de um acordo argumentativo estabelecido entre indivíduos livres e iguais. A obediência aos princípios acima apontados dá sustentação, segundo Cohen, a uma concepção de democracia deliberativa que articule processos com resultados, e que faça valer de fato as expressões "pelo povo" e "para o povo" que são próprias do ideal de democracia. Entre o conjunto de sujeitos deliberativos, o autor destaca o papel das associações "secundárias", na medida em que representam os interesses de uma ampla base social que, de outra forma, se encontra sub-representada. A atuação deste associativismo é fundamental para corrigir as desigualdades econômicas subjacentes e garantir "a competência regulatória requerida para a promoção do bem comum" ${ }^{5}$.

Diferente, portanto, da perspectiva R que "sustenta que o poder deve organizar-se democraticamente através de

\footnotetext{
${ }^{4}$ Como grupos organizados que são intermediários entre o mercado e o Estado (Cohen, 2000: 43).

${ }^{5}$ Cohen (2000:43).
} 
instituições que mediam a relação entre os interesses privados dos indivíduos e o poder" (Faria, 2000: 58), a perspectiva P sustenta-se, nesta vertente, na idéia de que o poder deve organizar-se democraticamente por instituições que, construídas coletivamente por intermédio de discussão pública, mediam as relações entre os interesses individuais e coletivos, na formação do interesse público a ser implementado pelo complexo administrativo estatal.

Tomando em conta, segundo análise de Pitkin (s.d [1967]), o sentido básico de participação (auto-apresentação) e de representação (tornar presente algo que está ausente), fica claro o peso diferenciado de cada um destes pólos nos diferentes modelos democráticos. Assim, no modelo representativo, a participação restringe-se ao momento da escolha dos representantes na ocasião do processo eleitoral. Aqui, a legitimidade do sistema democrático é dada pela manifestação eleitoral da vontade dos cidadãos

144 (Novaro, 1995). Em outras palavras, a responsabilidade do processo decisório fica restrita aos representantes escolhidos pelo sufrágio eleitoral.

Já os modelos participativos apresentam, de maneira geral, um critério de legitimidade ancorado na idéia de que as decisões políticas devem ser tomadas por aqueles que estarão submetidas a elas por meio do debate público. Com efeito, no plano teórico, as diferenças com relação ao modelo da democracia representativa são marcantes, já que incorpora a participação da população no processo de discussão e de tomada de decisões políticas. Tendo em vista a inevitabilidade da representação (na participação), a efetividade destes princípios de controle social vai ocorrer depõe meio de diferentes práticas de participação e representação (p\&r), cujas características, no tocante à representação, visam a superar os limites da representação eleitoral.

Não é à toa, portanto, que estes instrumentos analíticonormativos ancorados em P têm instruído os estudos empíri- 
cos acerca da participação. A reconstrução, ou consolidação de $\mathrm{R}$ no país, vem sendo acompanhada da avaliação de que o retorno às instituições formais básicas da democracia não tem se mostrado capaz de produzir respostas adequadas aos problemas de exclusão e de desigualdades sociais (Dagnino, 2002), requerendo a ativação da cidadania, no sentido de romper com uma noção de política como atividade exclusiva de "aparatos partidários oligarquizados e de políticos profissionais com vocação pública discutível” (Fontana, 2000). Com efeito, uma forte demanda pela institucionalização de $\mathrm{P}$ passa a caracterizar a atuação de diversos segmentos da sociedade civil organizada. Como resultante deste processo, o caráter público da sociedade civil amplia-se, na medida em que, para além dos debates, articulações, encontros que visam a discutir, problematizar questões e demandar soluções para os problemas que estão ausentes ou que recebem tratamento precário na agenda pública, produzindo e ampliando, portanto, os espaços públicos, significativos setores da sociedade civil passam também a demandar e/ou investir na implementação de espaços públicos institucionais, a exemplo dos Conselhos Gestores de Políticas Públicas e de experiências de Orçamento Participativo. No caso dos Conselhos Gestores, sua institucionalização, resultado de uma trajetória de lutas de diferentes segmentos sociais, apresenta uma natureza jurídica que imprime um caráter legal ao seu status deliberativo na definição, decisão e no controle das principais diretrizes e ações governamentais nas diferentes áreas de políticas sociais. No caso das experiências de Orçamentos Participativos, sua implementação - e seus diferentes formatos - encontram-se, em grande parte dos casos, dependentes do projeto político-partidário que assume o poder governamental.

A generalização destas experiências vai motivar, portanto, a incorporação de um referencial teórico que, como visto acima, guarda toda centralidade ao ideário da participação, 
em contraposição ao modelo da representação. De acordo com Gurza Lavalle, Houtzager e Castello (2006a), "autores debruçados sobre o aprimoramento da qualidade da democracia e, nesse sentido, orientados para a definição de uma agenda de reforma, pouca atenção têm prestado à questão da representação, a não ser para denunciar suas mazelas ou limitações e valorizar a democracia participativa" (Gurza Lavalle, Houtzager e Castello, 2006a: 2). A introdução da participação está relacionada, portanto, a uma avaliação positiva acerca da capacidade que as experiências participativas oferecem para "rebalancear a articulação entre a democracia representativa e a democracia participativa" (Avritzer, 2003).

Para além, entretanto, das tensões ou combinações entre $\mathrm{R}$ e $\mathrm{P}^{6}$, as experiências participativas inauguram novos mecanismos e relações de representação política que apresentam especificidades e diferenças substantivas com o modelo da representação eleitoral (R) (embora dele 146 sofram vários impactos), seja por combinarem, em seu interior, mecanismos de representação com participação direta; seja por articularem, de forma imediata, participação com representação da sociedade civil.

\section{Sociedade civil e participação}

A incorporação da teoria da "nova sociedade civil" no Brasil data dos anos de 1990 e segue uma orientação teórica mais geral de recomposição e difusão do conceito que, de acordo com Nogueira (2003), teve como base um conjunto de fatores, entre eles, a complexificação, diferenciação e fragmentação das sociedades contemporâneas que vêm testemunhando a diminuição do peso político da classe operária e registrando

\footnotetext{
${ }^{6}$ Sobre essas tensões, ver Silva (1999). Alguns estudos avaliam as tensões entre experiência participativa e outras esferas de poder institucional como a Câmara de Vereadores (Dias, 2000) e o executivo (Borba, 1998).

${ }^{7}$ Gurza Lavalle (1999 e 2003). 
a emergência de novos sujeitos coletivos; o processo da globalização que proporcionou, entre outros, uma maior transparência e autonomia do social ante a institucionalidade política; e a suposta crise da democracia representativa com, ou mediante, seus impactos negativos no "funcionamento e identidade dos partidos políticos de esquerda, já abalados pela dificuldade de reprodução dos sujeitos sociais 'clássicos' e pela diminuição do sentido das grandes utopias políticas” (2003: 188).

Neste processo de reconfiguração do conceito de sociedade civil, ganha destaque a concepção habermasiana (Habermas, 1997; Cohen e Arato, 1992) caracterizada, neste modelo teórico, por um conjunto de sujeitos coletivos que tematizam novas questões e problemas, que clamam por justiça social e que organizam e representam os interesses dos que são excluídos dos debates e deliberações políticas. Com efeito, construindo e ampliando a esfera pública, a sociedade civil passa a articular-se, ou a constituir-se em um núcleo central do conceito de democracia deliberativa.

A incorporação deste ideário pautado na sociedade civil traz, para o debate democrático, tanto superações como limitações. Para o primeiro caso, ressalto aqui duas dimensões correlatas, quais sejam, a dimensão que reintroduz, na discussão teórica acerca da política e da democracia, o valor e o papel da ação coletiva, tensionando a perspectiva liberal assentada na dimensão individual da política, e na relação - e redução - que estabelece entre a "sociedade civil com a esfera privada, entendida enquanto economia, com o Estado, entendido enquanto esfera pública" (Arato e Cohen, 1994: 162). Uma perspectiva tripartite promove, portanto, uma complexificação analítica ao diferenciar sociedade civil e mercado, resgatando uma dimensão dos conflitos que, na perspectiva liberal, vem sendo domesticada em nome do equilíbrio e da representação "do interesse público ou universal" (Pitkin, 2006: 38) a ser defendido por um punhado de representantes eleitos por sufrágio universal. 
Já os limites apontados à teoria da "nova sociedade civil" dizem respeito, entre outros, ao caráter "sobrestimado" das organizações da sociedade civil, através de uma perspectiva maniqueísta que vê nestas o pólo da virtude, em contraposição ao Estado, tido como encarnação do mal (Lavalle, 1999 e 2003; Dagnino, Olvera e Panfichi, 2006). A heterogeneidade da sociedade civil constitui-se, entre outros, como elemento de questionamento acerca da excessiva carga normativa do conceito que, ancorado na dicotomia entre sistema e "mundo da vida", acaba obscurecendo as relações - caracterizadas por tensões, ambigüidades e reproduções - entre a sociedade e o Estado, ou entre a sociedade civil e a sociedade política ${ }^{8}$.

Entre outros motivos, são exatamente as experiências de p\&r que vão contribuir para ir se encorpando um conjunto de críticas à teoria da "nova sociedade civil", dentre elas, o seu caráter homogeneizador, dicotomizador e maniqueísta 148 ante a sociedade política e/ou ao Estado (Dagnino, Olvera e Panfichi, 2006). Com efeito, percebeu-se que uma leitura teórica dava, a priori, uma legitimidade de participação e representação da sociedade civil que as evidências empíricas contestavam: a heterogeneidade de objetivos, interesses e formas de organização; os vínculos estreitos com o sistema político; e a influência do contexto na atuação e formulação política destes sujeitos coletivos desautoriza uma leitura que imprime uma natureza necessariamente democrática deste campo. De acordo com Gurza Lavalle, Houtzager e Castello (2006a), essa suposta relação imediata entre organizações sociais e interesses genuínos da sociedade (o mundo da vida), "tende a dissipar a formulação de questões como em nome de quem e mediante quais mecanismos de controle e responsividade representam as organizações civis" (Gurza Lavalle, Houtzager e Castello, 2006a: 46).

\footnotetext{
${ }^{8}$ Sem mencionar aqui as relações com o mercado.
} 
A adoção desta perspectiva teórica, que relaciona de forma intrínseca os termos democracia, participação e sociedade civil, está intimamente relacionada, no país, ao fato de que foram (fundamentalmente, mas não exclusivamente) as organizações deste campo as que lutaram pela implementação e institucionalização de espaços participativos de gestão de políticas públicas, espaços estes que, em grande medida, foram programados ou desenhados visando à incorporação de um tipo de participação política que ocorre através da representação das organizações da sociedade civil. Como veremos, os Conselhos Gestores constituem-se experiências exemplares nesse sentido. Nestes, a relação imediata entre organizações da sociedade civil e defesa de direitos dos setores excluídos vem tornando quase que automático o vínculo entre sociedade civil, participação e representação, o que requer uma maior problematização acerca do grau de legitimidade da representação destes atores no interior destes espaços.

Mesmo que outros tipos de experiências de representação e participação (p\&r) - a exemplo do Orçamento Participativo - estejam ancoradas em princípios de participação direta (individual) e de representação delegada, observa-se, também nestes espaços, o predomínio de um tipo de representação mediada pelas organizações da sociedade civil.

\section{Participação e representação nas experiências brasileiras}

Sabemos que já é bastante extenso o repertório de experiências, principalmente no âmbito do poder local, de introdução da participação nos espaços de discussão e decisão de políticas públicas, a exemplo dos Conselhos Gestores e dos Orçamentos Participativos. Sabemos também que, na maioria dos casos, a participação ocorre por intermédio do instrumento da representação, portanto, p\&r.

Transcorrida bem mais de uma década de implementação e institucionalização destes espaços participativos, percebe-se, pelas aproximações empíricas e por uma consulta mais 
cuidadosa nos diversos textos analíticos, uma boa listagem de desafios e limites em sua capacidade de promover alterações significativas em direção ao aprofundamento democrático. A ênfase dada à participação tende a obscurecer, no plano analítico, não apenas os impactos e influências do modelo de representação eleitoral sobre a participação, como os mecanismos de representação no interior dos próprios espaços participativos, ou seja, p\&r, cujas especificidades dizem respeito não apenas às diferenças com relação ao modelo R, como também às diferentes modalidades de p\&r. Senão vejamos.

No seu conjunto, podemos elencar algumas características de p\&r nos espaços de conselhos gestores e orçamentos participativos, quais sejam: participação e representação individual e coletiva; voluntária (e, portanto, radicalmente diferente da atuação política profissional e com todas as conseqüências desta implicação); em diferentes espaços participativos; e com escolha de representantes mediante processos variados (fóruns, eleições, indicações etc.). Este conjunto de características parece suficiente para imprimir algumas especificidades deste tipo de representação política diante do modelo R. Por outro lado, comparece, no interior destas similaridades, uma série de diferenças significativas nas relações entre participação e representação. Em se tratando de experiências brasileiras, percebemos, apesar das as múltiplas configurações e orientações, a relativa consolidação de, pelo menos, dois modelos que me parecem bastante expressivos na constituição - diferenciada - enquanto p\&r. Por um lado, o modelo dos conselhos que, como veremos, está pautado na idéia de participação coletiva, ou seja, pela representação das organizações da sociedade civil. Por outro lado, o orçamento participativo que, apresentando a configuração de uma "esfera pública essencialmente plebéia” (Baierle, 2005: 19), desenha um modelo que parece apresentar maior combinação entre participação direta (nas assembléias de bairros e regiões) e mecanismos de 
representação (via escolha de delegados e conselheiros), embora, como veremos, esteja também ancorado no instrumento de representação coletiva.

Não obstante compartilhem, de maneira geral, as características acima esboçadas, as diferenças quanto ao peso e à maior ou menor combinação entre a participação e representação individual e coletiva constituem-se, no meu entender, em elemento analítico importante no que se refere ao debate acerca da legitimidade da representação - seja por delegação de mandato, no caso do OP, seja por critérios de expertise ou qualificação, no caso dos conselhos, nos espaços de participação ${ }^{9}$.

Assim, percebe-se uma diversidade de regras e critérios de representação no interior dos espaços participativos. Esta diversidade instaura uma confusa compreensão acerca dos critérios de legitimidade política destes espaços, se comparados aos critérios de legitimidade de R. Vejamos brevemente os casos dos Conselhos gestores e dos orçamentos participativos.

Os conselhos gestores de políticas públicas são conselhos amparados por legislação nacional e apresentam um caráter decisório (de política pública) mais estruturado e sistêmico, sendo previstos de atuarem nas três esferas governamentais (município, estado e no plano nacional). Apresentam "atribuições legalmente estabelecidas no plano da formulação e implementação das políticas na respecti-

\footnotetext{
${ }^{9}$ Agradeço a Adrián Gurza Lavalle pela leitura criteriosa e pelos comentários a este trabalho, dentre eles, a especificação de algumas diferenças no tipo de representação destes espaços: "Os Conselhos operam com uma representação coletiva de jure, enquanto o OP opera simultaneamente com uma representação coletiva de fato (os sujeitos que lá estão representando alguma entidade nos diferentes ciclos) e com uma representação internamente construída pelo processo institucional (delegados e conselheiros escolhidos por cidadãos 'avulsos' e por representantes de entidades). Por fim, os Conselhos alimentam práticas de representação por advocacy ou próximas da idéia de representação virtual, enquanto no OP a eventual presença desse tipo de práticas acaba subordinada a alguma modalidade de representação por mandato (isso, desnecessário explicar, não cancela a autonomia e independência dos representantes)".
} 
va esfera governamental, compondo as práticas de planejamento e fiscalização das ações. São também concebidos como fóruns públicos de captação de demandas e pactuação de interesses específicos dos diversos grupos sociais e como uma forma de ampliar a participação dos segmentos com menos acesso ao aparelho de Estado" "10. Estão voltados à garantia de universalização dos direitos sociais. Entre eles, destacam-se os Conselhos de Saúde, de Assistência Social, de Defesa dos Direitos da Criança e do Adolescente.

No que diz respeito à relação entre participação e representação (p\&r), duas características centrais destes espaços são: a participação de entidades ou organizações da sociedade civil e a paridade ${ }^{11}$ na representação entre sociedade civil e Estado. De acordo com as suas respectivas leis de criação $^{12}$, pode-se observar a dimensão da representação coletiva por meio de entidades não-governamentais ${ }^{13}$ (Criança

\footnotetext{
${ }^{10}$ Comunidade Solidária/IBAM/IPEA.

${ }^{11}$ No conselho de saúde, o peso maior da representação recai cobre o setor dos usuários que detém $50 \%$ de seus assentos.

${ }^{12}$ Aspectos da legislação referente à participação e representação nos Conselhos Gestores: Saúde (Lei 8.142, de 28 de dezembro de 1990): "O Conselho de Saúde, em caráter permanente e deliberativo, órgão colegiado composto por representantes do governo, prestadores de serviço, profissionais de saúde e usuários, atua na formulação de estratégias e no controle da execução da política de saúde na instância correspondente, inclusive nos aspectos econômicos e financeiros, cujas decisões serão homologadas pelo chefe do poder legalmente constituído em cada esfera do governo". Criança e Adolescente (Lei 8.242, de 12 de outubro de 1991): "O Conanda é integrado por representantes do Poder Executivo, assegurada a participação dos órgãos executores das políticas sociais básicas na área de ação social, justiça, educação, saúde, economia, trabalho e previdência social e, em igual número, por representantes de entidades não-governamentais de âmbito nacional de atendimento dos direitos da criança e do adolescente". Assistência Social (Lei 8.742, de 7 de dezembro de 1993): "A organização da assistência social tem como base as seguintes diretrizes: I - descentralização político-administrativa e comando único das ações em cada esfera de governo; II - participação da população, por meio de organizações representativas, na formulação das políticas e no controle das ações em todos os níveis. As instâncias deliberativas do sistema descentralizado e participativo de assistência social, de caráter permanente e composição paritária entre governo e sociedade civil".

${ }^{13}$ Embora a legislação do Conselho de Saúde não especifique a representação co-
} letiva, a lista de representantes deixa clara esta dimensão. 
e adolescente) ou organizações representativas (Assistência social), bem como a questão da paridade, seja entre Estado e sociedade (Criança e adolescente; Assistência social), seja entre usuários e demais setores (Saúde).

Os conselhos gestores apresentam diferenças, ou especificidades, que vão do número de assentos, passando pelo perfil dos segmentos representados e dos mecanismos de escolha desses representantes. Alguns setores escolhem seus representantes em assembléias ou fóruns abertos. Outros segmentos já estão de antemão inseridos (pela legislação) na composição dos conselhos ${ }^{14}$. Por outras palavras, os mecanismos de escolha oscilam de caso a caso: em uma única assembléia com a participação de diferentes atores e organizações sociais; por meio de fóruns setoriais de políticas públicas ou de assembléias, ou indicações de categorias profissionais. Mesmo que se trate da articulação em assembléias e fóruns, apesar da maior "organicidade" com as "bases", esta representação mantém certos limites circunscritos pela "lógica dos mobilizados", ou de um conjunto de organizações que apresentam uma representação presuntiva (Gurza Lavalle, Houtzager e Castello, 2006b) ancorada na idéia de que a sociedade civil representa (independente de mecanismos formais) genuínos interesses sociais. Trata-se, portanto, de uma idéia de representatividade que alimenta certa confusão no entendimento acerca dos critérios de legitimidade que estes espaços carregam, na medida em que ora se apela para a legitimidade da representação de pessoas ou setores com "uma história feita' nas 'lutas' dos segmentos pró-cidadania” (Tatagiba, 2002); ora se relaciona legitimidade com qualificação e competência dos representantes, como tem sido o caso das ONGs (Dagnino, 2002); ora o critério de legitimidade está

${ }^{14}$ Como no caso de sindicatos, federações de associações de moradores, entidades profissionais etc. 
ancorado na capacidade dos representantes em "expressar os interesses do respectivo segmento social" (Teixeira, 1996: 15).

Com efeito, estamos tratando de um tipo de representação que, diferente do modelo eleitoral que identifica o representado (eleitor), esboça uma idéia difusa dele mesmo, podendo tanto ser um segmento (ou vários setores da população), quanto a própria entidade indicada para assumir a representação. $O$ caso da representação das ONGs nos conselhos é bastante emblemático, uma vez que, como analisa Sorj (2005), estas organizações apresentam a especificidade dada pelo fato de se constituírem num "ator sem mandato direto de sua base de referência" (Sorj, 2005: 21). Tendo em vista que muitas organizações são escolhidas muito mais em função de seu grau de competência e qualificação do que em virtude de seu vínculo com as bases, altera-se sobremaneira o debate acerca das exigên154 cias de prestação de contas, responsividade e sanção. Não é de se estranhar, portanto, o perfil dos conselheiros que, de acordo com Santos Junior, Azevedo e Ribeiro (2004), constituem uma espécie de elite de referência, ou de uma comunidade cívica (Santos Junior, Azevedo e Ribeiro, 2004: 37) portadora de uma cultura associativa caracterizada por um perfil socioeconômico superior e por maior grau de informação e de capacitação técnica e política se comparada à média da população em geral.

Como resultante geral, a composição dos conselhos conjuga, digamos, participação coletiva (auto-apresentação das entidades escolhidas como tal) com representação coletiva (entidades escolhidas por representarem - por critérios variados - outros setores sociais). Aqui, a representação por entidades, ou organizações da sociedade civil, está difusamente ancorada na legitimidade destas organizações em promover, de diferentes formas, a defesa das variadas "causas" sociais e de demandas e interesses de grupos e setores 
sociais historicamente excluídos dos processos de decisão política. Poder-se-ia dizer, portanto, que a representação nos conselhos apresenta maior grau de independência, na medida em que está relacionada com a formulação de políticas públicas e, portanto, pautada na perspectiva de representação de interesses gerais.

No caso das experiências de orçamento participativo, embora também ocorram variados mecanismos de participação e representação - de acordo com cada experiência concreta -, constitui-se como um modelo que institui o tipo de representação delegada que, de acordo com Bobbio (1987), apresenta vínculos mais estreitos com a defesa de interesses mais específicos e/ou particulares. De maneira geral, entende-se o orçamento participativo como modelo de gestão, que abre a participação da população nas discussões e definições da peça orçamentária, fundamentalmente na esfera municipal. Diferente dos Conselhos que estão previstos em legislação, sua implementação está mais diretamente vinculada à conquista de diversas prefeituras por parte de governos de esquerda, notadamente do Partido dos Trabalhadores ${ }^{15}$. Tratar-se-ia, portanto, de um modelo de administração que apresenta como premissa básica o fato de que a população não apenas deve ser consultada quanto às demandas de investimento do poder público, como também deve ser capacitada para deliberar acerca das prioridades, participando ativamente da própria execução e controle do orçamento público.

\footnotetext{
${ }^{15}$ Embora diversos partidos tenham, de forma diferenciada, implementado mecanismos participativos e, em alguns casos, antes mesmo da redemocratização (exemplo paradigmático de Lages), a centralidade do PT neste processo diz respeito ao seu programa cuja ênfase na "democracia popular" marcou o eixo norteador do "modo petista de governar" (Meneguello, 1989). Foi com a vitória do PT nas eleições municipais de 1988 na capital e em importantes cidades do Estado de São Paulo (São Bernardo do Campo, Santo André, Diadema, Campinas, Piracicaba e Santos) e nas capitais do Rio Grande do Sul e Espírito Santo que efetivamente se instituiu um conjunto de mecanismos participativos, a exemplo do Orçamento Participativo.
} 
A disseminação da experiência, tendo como modelo Porto Alegre ${ }^{16}$, vem instigando a construção de uma definição do OP como articulação entre democracia representativa e democracia participativa que, de acordo com Avritzer (2003), se baseia em quatro elementos, quais sejam: a cessão da soberania pelos detentores dos cargos eletivos do poder executivo, pela criação de um conjunto de espaços participativos (assembléias regionais e temáticas) nos quais todos os cidadãos podem participar com igual poder de deliberação; a articulação da participação local ou direta, por intermédio das assembléias regionais, com mecanismos de delegação, mediante escolha de delegados e conselheiros nas esferas de representação regional e municipal; a autodeterminação na formulação das regras e critérios de participação e distribuição de recursos, "vinculando o OP a uma tradição de reconstituição de uma gramática social participativa na qual as regras da deliberação são determinadas pelos próprios participantes (Avritzer. 2003: 15); e por último, o objetivo de promoção da reversão das prioridades na distribuição dos recursos públicos, privilegiando os setores mais carentes da população.

Diferente dos conselhos gestores, a organização e a metodologia de discussões e de deliberação do orçamento participativo estão assentadas, nas experiências que seguem o modelo de Porto Alegre, em um conjunto de espaços que articulam o local (bairro) com a região e com o contexto municipal mais geral (cidade). Apresenta diferentes níveis de participação, que vai da esfera local e regional, caracterizada pela participação direta (em associações de bairro, conselhos populares, clubes de mães, assembléias regionais) que se articula com a representação dos delegados nos fóruns

\footnotetext{
${ }^{16}$ Inserida no âmbito da "administração popular" capitaneada pelo PT com a vitória nas eleições municipais de 1989, o OP de Porto Alegre vem sendo tomado como paradigma de uma experiência que tem servido como modelo para centenas de municípios no país (e no exterior).
} 
regionais e, finalmente, com os conselheiros do Conselho do Orçamento Participativo, responsáveis pela discussão do orçamento confrontando o conjunto das demandas regionais. À articulação entre a participação direta e a representação segue-se uma articulação entre os diversos fóruns, fundamentalmente pelo procedimento de regionalização. Assim, o processo desenvolve-se de forma piramidal, conjugando a representação delegada (delegados e conselheiros com mandato revogável ${ }^{17}$ ) às assembléias locais e regionais.

Mesmo que não tenha sido previsto no plano regimental, percebe-se aqui, assim como nos conselhos gestores, uma íntima articulação entre representação e associativismo civil. Sabemos que uma ampla maioria dos representantes (delegados e conselheiros) participa de organizações civis com predomínio do associativismo comunitário. Entretanto, o desenho do OP parece promover combinações mais complexas entre participação e representação, na medida em que conjuga - não sem problemas - participação individual e coletiva com representação individual (e coletiva). Este, aliado evidentemente às diferentes características ou tipos de políticas públicas em jogo, pode ser um elemento importante para a compreensão do fato de que o perfil geral dos participantes do OP registra alguma diferença com relação ao perfil dos representantes nos conselhos gestores. No caso do OP, a participação direta dos cidadãos nas assembléias tem desenhado um perfil mais popular, na medida em que:

"A grande maioria dos participantes do OP pertence às classes populares são trabalhadores sem qualificação, a maioria mulheres, com escolaridade primária, renda

\footnotetext{
${ }^{17}$ De acordo com o artigo 23 do Regimento Interno do OP de Porto Alegre (PMPA, 2001), a revogação do mandato dos conselheiros(as) "dar-se-á por deliberação de (2/3) dois terços dos presentes no fórum de delegados(as) regional ou temático do Orçamento Participativo, conforme o caso, garantindo o quorum mínimo de metade mais um dos delegados(as) eleitos" (PMPA, 2001: 14).
} 
familiar mensal inferior a $\mathbf{R} \$ 1.000,00$ e uma forte presença de negros e de descendentes indígenas, numa cidade onde a grande maioria se considera branca. Mesmo que, para o COP, haja uma certa variação nesse perfil, sobretudo em termos de renda, escolaridade e gênero, já que não se alteram relações seculares pela simples mágica de um novo desenho institucional, o importante é observar as tendências de fundo, a participação crescente das mulheres, o aumento constante do número de participantes e o 'fio terra' que prende os representantes às suas bases regionais e temáticas: o controle dos representantes diretamente pelos representados, podendo os conselheiros ter o seu mandato revogado por decisão do fórum de delegados em reunião especialmente convocada para esse fim" (Baierle, 2005: 22).

Assim, no seu conjunto, conselhos gestores e orçamentos participativos constituem-se exemplos de práticas de participação e representação (p\&r) que apresentam especificidades com relação ao modelo da representação eleitoral (R), seja pela incorporação de elementos de participação (individual e coletiva) direta $(\mathrm{P})$, seja pela criação de novos espaços e critérios de representação. As relações p\&r que caracterizam estas experiências apresentam também diferenças e especificidades entre os modelos.

No caso dos conselhos gestores, observamos dois tipos de participação como auto-apresentação, embora ambos sejam minoritários no interior destas experiências: por um lado, a participação direta dos cidadãos, que se restringe aos rarefeitos momentos de organização de fóruns ou conferências (municipal, estadual e federal); e por outro lado, a participação dos segmentos da sociedade civil escolhidos por critérios de qualificação. Apesar da ocorrência destes instrumentos, este modelo está predominantemente ancorado em um princípio da representação que ocorre por intermédio das organizações da sociedade civil. Com efei- 
to, este procedimento traz algumas ambigüidades no que se refere às promessas da democracia participativa e deliberativa. Por um lado, a representação por segmentos (ou organizações sociais) reproduz, no espaço institucional, um processo de filtragem que, operacionalizado pela lógica associativa, recorta o campo da representação, que passa a ser eminentemente ocupado pelos setores que apresentam maior nível socioeconômico e cultural. Sabemos que a redução dos sujeitos participativos traz alguns desconfortos para a teoria democrática. Por outro lado, as clivagens no campo da sociedade civil (e do Estado) tensionam o ideal de paridade, estimulando reformulações em direção à maior pluralização dos sujeitos e setores participativos. Este parece ser o caso da área da saúde, que vem testemunhando, historicamente, alterações importantes no perfil de seus representantes. Talvez esta pluralidade seja a chave (democrática) para a coexistência das diferentes noções de legitimidade - ora em referência aos grupos e entidades que, historicamente, lideraram as lutas por direitos, ora remetida ao grau de qualificação (técnica e política) ou, ainda, aos públicos por elas representados.

Já o modelo do OP, por prever a participação direta dos cidadãos, independente de vínculos associativos, apresenta maior capacidade de inclusão dos setores ou indivíduos mais empobrecidos da população. Aqui, a representação (via delegados e conselheiros) desenha um sistema que se aproxima de um tipo piramidal de articulação entre a participação da base nas assembléias regionais e representação (Fóruns de delegados e COP), por meio de mecanismos (mandato revogável) que permitem maior controle dos representantes diante dos representados. O perfil socioeconômico dos participantes do OP é um importante indicador da adoção de um critério de legitimidade pautado na idéia de inclusão social. Diferente do desenho ancorado na paridade (nos conselhos) que parece fortemente instruído 
pelo ideário da sociedade civil, a regra da maioria (no OP) está vinculada a um projeto orientado para a ampliação da participação dos setores historicamente excluídos do cenário das decisões governamentais.

Por tratar de questões que afetam de forma mais direta a população - e notadamente os setores mais carentes e dependentes dos serviços estatais - o OP apresenta um importante potencial de motivação à participação. Além disso, a participação e a adesão ao processo do orçamento participativo revelam uma coincidência de interesses sociais e políticos devido aos objetivos e resultados do OP, que vem se mostrando como alternativa confiável ${ }^{18}$ de resolução das demandas sociais. Trata-se, portanto, de uma política de soma positiva: o Estado mantém e aumenta sua legitimidade e capacidade de implementação de políticas, bem como a população vê atendidas as reivindicações que foram por ela demandadas. Apresenta forte capacidade de formação de consensos não apenas em função deste compartilhamento de interesses, como também de uma maior capacidade de incorporação de lideranças sociais que, compartilhando do mesmo projeto político, passam a atuar no interior da estrutura governamental.

No caso dos conselhos gestores que tratam da discussão e definição de políticas mais gerais, o caráter da aproximação e da concreticidade da relação demanda-resolução não se efetiva como no caso das experiências de OP, o que limita (e muito) a motivação à participação. Seguindo este ponto de vista, parece bastante compreensível a baixa freqüência participativa nos conselhos gestores, se comparados ao OP. O tipo de política diz muito não apenas no que se refere à maior ou menor proximidade com os interesses da população, como também no que diz respeito ${ }^{18}$ Pesquisa em OPs do Estado de Santa Catarina indica altos índices de confiança
dos delegados e conselheiros no processo (Borba et al., 2006). 
ao quadro de alcance social e de complexidade institucional. Soraya Côrtes (2002) analisa, por exemplo, algumas diferenças nas áreas das políticas de saúde e de assistência social que vão impactar a participação nos respectivos conselhos gestores. De acordo com a autora, "os recursos financeiros, a quantidade e a complexidade dos serviços, as dimensões da estrutura administrativa da área no contexto da administração municipal e, mesmo, a natureza da população coberta pelos serviços e benefícios oferecidos afetam negativamente a importância relativa da assistência social em comparação com a saúde"(Côrtes, 2002: 201). Como resultado geral, os conselhos da área da saúde apresentam uma dinâmica de funcionamento e de representação mais substantiva - e deliberativa - se comparado à dinâmica na área de assistência social, com características eminentemente gerenciais.

Assim, os diferentes desenhos institucionais ${ }^{19}$, ou as diferentes configurações entre participação e representação, bem como os diferentes tipos de políticas públicas são, entre outros, elementos centrais para o entendimento das diferentes dinâmicas de p\&r entre os modelos analisados. A dimensão da participação está em estreita articulação com a questão da representação, em variadas configurações.

Dessa forma, se no plano empírico a dimensão da representação (nas práticas p\&r) se sobressai, haja vista a impossibilidade e os limites da participação direta no mundo contemporâneo, no plano teórico, há que se avançar na formulação de um quadro analítico que busque qualificar esta nova dimensão da representação, tendo em vista superar os limites e desafios das práticas e mecanismos de controle social. Pensado e ancorado no modelo da representação eleitoral, o debate acerca da representação carece aqui de importantes reavaliações.

\footnotetext{
${ }^{19}$ Lüchmann (2002a e 2002b).
} 


\section{Em direção a uma outra concepção de representação}

De acordo com Bobbio (1987), a participação direta ocorre em basicamente dois momentos: a assembléia dos cidadãos deliberantes sem intermediários e o referendum, e todas as outras formas de participação ocorrem via representação. No que diz respeito especificamente à representação, o autor salienta a relação que existe, "de um lado, entre a figura do representante como delegado e a da representação dos interesses particulares, e de outro lado entre a figura do representante como fiduciário e a representação dos interesses gerais" (Bobbio, 1987: 46).

Analisando nesses termos, poder-se-ia dizer que conselhos e OPs personificam, na prática, as relações que existem entre, de um lado, a figura do representante como delegado na representação de interesses particulares (no caso do OP); e, de outro lado, a figura do representante como fiduciário e a representação dos interesses gerais (no caso dos conselhos). Entretanto, estas experiências p\&r parecem desautorizar uma incorporação imediata das formulações teóricas endereçadas historicamente ao modelo da representação eleitoral (R). Ou seja, estas experiências trazem à tona algumas novidades - e especificidades - que parecem desafiar o referencial analítico disponível acerca da representação política.

Em primeiro lugar, a dimensão da participação e representação coletiva. Como vimos, mesmo de formas diferentes, as experiências estão ancoradas na idéia de que a participação (e representação) pode ocorrer por intermédio das organizações da sociedade civil. A participação direta, portanto, extrapola a dimensão individual, como são os casos das organizações e associações que ocupam lugares estratégicos na sociedade civil.

Esta dimensão deixa mais complexa aquela tipologia fundamentada nos dois modelos de representação. Em análise acerca da representação política de grupos 
(minorias ou excluídos), Young (2006) oferece algumas idéias promissoras para o debate acerca dessa dimensão. Com o objetivo de enfrentar a dualidade, ou "falsa dicotomia” entre representação por delegação/identidade versus representação por substituição/independência nas relações entre representantes e representados, ou ainda, em vez de entender a representação política como ato de "pôr-se" pelos eleitores, a autora analisa a questão da representação lançando luz sobre o caráter do relacionamento entre o representante e os eleitores. Com efeito, "o representante inevitavelmente irá se afastar dos eleitores, mas também deve estar de alguma forma conectado a eles, assim como os eleitores devem estar conectados entre si”(2006: 149) ${ }^{20}$. A idéia de representação por perspectiva social ${ }^{21}$ visa a melhor corresponder, tendo em vista as diferentes inserções estruturais dos grupos e indivíduos, a esta necessidade de conexão, na medida em que diz respeito ao compartilhamento ou afinidade de olhares acerca dos processos sociais em função da posição que neles ocupam: "a perspectiva é uma abordagem da maneira de olhar eventos sociais, a qual condiciona, mas não determina o que se vê" (Young, 2006: 166).

Esta idéia de perspectiva de certa forma se aproxima do resgate da noção de representação virtual de Edmund Burke, sugerida por Gurza Lavalle, Houtzager e Castello (2006a) ${ }^{22}$, uma vez que, diferente da representação de interesses e opiniões (e ainda, da representação descritiva ou como

\footnotetext{
${ }^{20}$ Uma análise do trabalho de Young encontra-se em Pinto (2004).

${ }^{21}$ Diferente, embora inter-relacionada, com a representação de interesses e de opiniões (Young, 2006).

${ }^{22} \mathrm{O}$ resgate da idéia burkeana de representação virtual como existência de compromisso genuíno com os representados encontra guarida, de acordo com os autores, nos usos contemporâneos de advocacy, caracterizada como "representação destinada a dar voz - algo distinto da função de ser porta-voz própria de práticas de representação coletivas englobadas claramente na idéia de grupos de interesse" (Gurza Lavalle, Houtzager e Castello, (2006a: 91).
} 
espelho) ${ }^{23}$, diz respeito a uma idéia de representação que "necessariamente envolve distinção e separação entre representantes e eleitores [...] em que a desconexão é sempre uma possibilidade e a conexão é mantida ao longo do tempo por meio de antecipações e retomadas em momentos de autorização e prestação de contas" (Young, 2006: 152).

Ao sugerirem que o fenômeno da representação que vem ocorrendo por meio do protagonismo adquirido por atores da sociedade civil, portanto, da representação coletiva, guarda semelhanças com a idéia de representação virtual, Gurza Lavalle, Houtzager e Castello (2006a) dão destaque, exemplificando com o trabalho de advocacy, a um tipo de representação que, embora compreenda, difere de configurar-se apenas como a vocalização difusa de causas diversas, na medida em que "desempenha também funções de intermediação perante o poder público na forma de representação virtual, ou seja, da defesa de interesses 164 que não autorizaram essa defesa ou que, embora simpáticos a ela, carecem de qualquer mecanismo estável para controlá-la ou comunicar-lhe preferências"(Gurza Lavalle, Houtzager e Castello, 2006a: 92). De alguma forma, subjaz aqui a dimensão do compartilhamento de olhares e perspectivas entre representantes e representados, embora não necessariamente compartilhem as mesmas posições na estrutura social. Este parece ser o caso da representação de várias organizações da sociedade civil nos conselhos gestores.

Entretanto, há que se resgatar alguns elementos que são centrais na idéia de representação, quais sejam, os mecanismos de autorização e de prestação de contas. Gurza Lavalle, Houtzager e Castello (2006a) advertem que, "malgrado existam diversos elementos que sugerem o potencial de representatividade da representação coletiva como um

\footnotetext{
${ }^{23}$ As quais guardam também um grau de legitimidade.
} 
expediente de reforma da democracia, sua problematização teórica e sua defesa pública esbarram em limites evidentes, a saber, a ausência de mecanismos generalizados, formais e estáveis de ordenação da relação entre atores da sociedade civil e seus públicos, beneficiários ou comunidades - notadamente mecanismos de autorização, prestação de contas, responsividade e sanção" (2006a: 87). Mesmo com as variações e apesar delas, este parece ser também o caso da representação nos conselhos gestores.

É aqui que se insere um segundo elemento deste debate, qual seja, a necessidade de focar o olhar para além das relações entre representantes e representados, isto é, para as relações entre os próprios representados. Este ponto relações entre os representados - constitui-se, no meu entender, em um marcador importante nas diferenças entre as teorias democráticas pautadas, por um lado, na representação (R) e, por outro, na participação $(\mathrm{P})$. No caso das teorias que dão projeção a $\mathrm{P}$, a noção de esfera pública ${ }^{24}$ parece central, na medida em que diz respeito à constituição de espaços de interação e discussão em que "os indivíduos interagem uns com os outros, debatem as decisões tomadas pelas autoridades políticas, discutem o conteúdo moral das diferentes relações existentes no nível da sociedade e apresentam demandas ao Estado" (Avritzer, 2000: 78).

Assim, uma representação legítima requer uma participação ativa por parte dos indivíduos, grupos e organizações sociais. Recorro novamente a Young (2006), na medida em que traz à tona a idéia de que uma representação legítima e inclusiva impõe responsabilidades tanto para os representantes como para os cidadãos: "estes precisam estar dispostos e aptos a mobilizar uns aos outros para participar ativamente tanto do processo de autorização quanto do de prestação de contas. Os representantes devem ouvir essas discussões

${ }^{24}$ Na perspectiva habermasiana (Habermas, 1997). 
públicas e as diversas demandas, permanecer conectados com os eleitores e expor as razões de suas ações e avaliações em termos que retomem aquelas discussões. Essa mobilização e essa conectividade podem ser promovidas ou obstadas pelo desenho das instituições representativas" (Young, 2006: 156). Assim, a qualidade e a legitimidade da representação vão depender do grau de articulação e organização da sociedade civil, ou seja, da participação. Os fóruns de discussão de políticas públicas e de definição e escolha dos representantes, no caso dos conselhos, ou as assembléias regionais e temáticas, no caso do orçamento participativo, podem ser exemplos de espaços públicos que promovem esta conexão entre representantes e representados.

Estes espaços ou esferas públicas de debate e conexão mobilizam um terceiro elemento de diferenciação com relação à perspectiva da representação (R) ancorada na idéia de agregação de preferências, ou seja, na idéia de que "a sociedade é a soma de indivíduos dissociados que competem e se unem, votam e agregam preferências por atos discretos de livre escolha e cálculo instrumental" ${ }^{25}$. A idéia de representação vinculada à noção de esfera pública prioriza a dimensão do debate público para a reformulação das opiniões e preferências: "a deliberação estimularia as pessoas não apenas a expressar suas opiniões políticas, mas também a formar essas opiniões através do debate público" (Vitullo, 2000). Com efeito, nessa concepção, um processo de autorização eficaz está ancorado no pressuposto de que a representação ocorre por intermédio de um movimento de distanciamento e aproximação entre representantes e representados, movimento este mediado pela constituição de esferas públicas de discussão e de debate que definem agendas e reavaliam, pela troca de experiências, informa-

\footnotetext{
${ }^{25}$ Urbinati (2006) em análise que diferencia democracia representativa de democracia eleitoral.
} 
ções e opiniões, as ações e direções da representação. Afinal, "são as idéias e opiniões (ou seja, o juízo em um sentido amplo) que são politicamente representados, e não indivíduos" (Urbinati, 2006: 223).

Assim, participação e representação coletivas, relações que extrapolam a dimensão representante e representado por intermédio de um foco orientado para as relações entre os representados ${ }^{26}$; e formação de opiniões e preferências são elementos que desafiam novos olhares para a fenômeno da representação política nos espaços de participação. As experiências participativas no Brasil, a exemplo dos conselhos gestores e do orçamento participativo (experiências p\&r), apontam para um movimento de renovação e de reacomodação destes instrumentos de ação política no interior das práticas institucionais da sociedade brasileira, indicando que, muito menos do que oposição, estes instrumentos estabelecem combinações e articulações que desenham um processo de concomitante inovação e reprodução das práticas e orientações político-institucionais. Apontam, sobretudo, para o fato de que a participação não substitui, mas reconfigura a representação, constituindo-se a participação em chave da boa representação.

\section{Lígia Helena Hahn Lüchmann}

é professora do Departamento de Sociologia e Ciência Política da Universidade Federal de Santa Catarina (UFSC)

\section{Referências bibliográficas}

ARATO, A.; COHEN, J. 1994. "Sociedade civil e teoria social". In: AVRITZER, L. (Org.). Sociedade civil e democratização. Belo Horizonte: Del Rey.

AVRITZER, L. 2000. "Teoría democrática, esfera pública y deliberación”. Metapolítica. México, v. 4, n. 14, p. 76-78, abr./jun.

. 2003. "O orçamento participativo e a teoria democrática: um

balanço crítico”. In: AVRITZER, L.; NAVARRO, Z. (Orgs.). A inovação democrática no Brasil: o orçamento participativo. São Paulo: Cortez.

${ }^{26}$ Além da importância das relações entre os primeiros. 
BAIERLE, S. 2005. Lutas em Porto Alegre: entre a revolução politica e o transformismo. Porto Alegre: Mapas, dez. Relatório de Pesquisa.

BOBBIO, N. 1987. O futuro da democracia: uma defesa das regras do jogo. Rio de Janeiro: Paz e terra.

BOHMAN, J. 2000. "La democracia deliberativa u sus críticos". Metapolítica, México, v. 4, n. 14, p. 48-57, abr./jun.

BORBA, J. 1998. A burocracia estatal frente a reforma do Estado em gestões democrático-populares: o caso da Secretaria de Planejamento Municipal de Porto Alegre, no período 1989-1996. Florianópolis: UFSC. Dissertação de Mestrado em Sociologia Política.

; LÜCHMANN, L. H. H. 2006. Orçamento Participativo: uma análise das experiências desenvolvidas em Santa Catarina. Florianópolis: UFSC. Relatório de pesquisa.

. 2005. "Modelos de desenho institucional em orçamentos participativos: as experiências de Santa Catarina”. Grifos, Chapecó: Argus.

COHEN, J. 1999. "Deliberation and democratic legitimacy". In: BOHMAN, J: REGH, W. Deliberative democracy. Essays on reason and politics. Massachusetts: Institute of Tecnology.

. 2000. "Procedimiento y sustancia en la democracia deliberativa”. Metapolítica, México, v. 4, n. 14, p. 24-47, abr./jun..

COHEN, J.; ARATO, A. 1992. Civil society and political theory. Cambridge: The Mit Press.

CÔRTES, S. M. V. 2002. "Participação de usuários nos conselhos municipais de saúde e de assistência social de Porto Alegre”. In: PERISSINOTTO, e FUKS, M. (Orgs.). Democracia, teoria e prática. Rio de Janeiro: Relume Dumará.

DAGNINO, E. 2002. "Sociedade civil, espaços públicos e a construção democrática no Brasil: limites e possibilidades”. In: DAGNINO, E. (Org.). Sociedade civil e espaços públicos no Brasil. Rio de Janeiro: Paz e Terra. p. 279-301.

; OLVERA, A. J.; PANFICHI, A. 2006. "Para uma outra leitura da disputa pela construção democrática na América Latina”. In: DAGNINO, E., OLVERA, A. J. e PANFICHI, A. (Orgs.). A disputa pela construção democrática na América Latina. São Paulo: Paz e Terra; Campinas: Unicamp.

DIAS, M. R. 2000. Na Encruzilhada da teoria democrática: efeitos do orçamento participativo sobre a Câmara Municipal de Porto Alegre. Rio de Janeiro: 211f. Tese de Doutorado. Instituto Universitário de Pesquisas do Rio de Janeiro.

FARIA, C. F. 2000. "El Concepto de Democracia Deliberativa. Un diálogo entre Habermas, Cohen y Bohman”. Metapolítica, México, v. 4, n. 14: 5875 , abr./jun.

FONTANA, R. 2000. "Uma novidade política”. In: GRANDO, S. (Org.). Floria- 
Lígia Helena Hahn Lüchmann

nópolis de todos. Florianópolis: Insular.

HABERMAS, J. 1997. Direito e democracia: entre facticidade e validade. Rio Janeiro: Tempo Brasileiro. v. 2.

HELD, D. 1987. Modelos de democracia. Belo Horizonte: Paidéia.

GURZA LAVALLE, A. 1999. "Crítica ao modelo da nova sociedade civil". Lua Nova. São Paulo: Cedec, n. 47.

. 2003. "Sem pena nem glória. O debate da sociedade civil nos anos 1990”. Novos Estudos, Cebrap, n. 66.

; HOUTZAGER: P.; CASTELLO, G. 2006a. "Democracia, pluralização da representação política e sociedade civil”. Lua Nova. São Paulo: Cedec, n. 67. ;___ 2006b. "Representação política e organizações civis. Novas instâncias de mediação e os desafios da legitimidade”. RBCS, vol. 21, n. 60, fev.

LÜCHMANN, L. H. H. 2002a. "Os Conselhos Gestores de Políticas Públicas: desafios do desenho institucional”. Revista de Ciências Sociais Unisinos, n. 161, p. 43-79, jul-dez.

2002b. Possibilidades e limites da democracia deliberativa: a experiência do Orçamento Participativo de Porto Alegre. Campinas: Unicamp. Tese de doutorado em Ciências Sociais.

MACPHERSON, C. B. 1978. A democracia liberal: origens e evolução. Rio de Janeiro: Zahar.

MENEGUELLO, R. 1989. PT a formação de um partido: 1979-1982. São Paulo: Paz e Terra.

MIGUEL, L. F. 2005. "Teoria democrática atual: esboço de mapeamento". BIB. São Paulo, n. 59, p. 5-42.

MOREIRA, M. T. V. 1999. "Instâncias deliberativas dos sistemas descentralizados e participativos das políticas públicas de cunho social: contorno jurídico dos conselhos". Informativo Cepam, São Paulo, ano 1, n. 1, mar. NOGUEIRA, M. A. 2003. "Sociedade civil, entre o político-estatal e o universo gerencial”. $R B C S$, v. 18 , n. 52, jun.

NOVARO, M. 1995. O debate contemporâneo sobre a representação política. Novos Estudos, n. 42, julho.

PATEMAN, C. 1992. Participação e teoria democrática. Rio de Janeiro: Paz e Terra.

PINTO, C.R. J. 2004. "Espaços deliberativos e a questão da representação". RBCS. São Paulo, v. 19 n. 54, fev.

PITKIN, H. F. s.d [1967]. "O conceito de representação". In: CARDOSO, F. H.; MARTINS, C. E. Política E̋ Sociedade. São Paulo: Cia. Editora Nacional. 2006. "Representação: palavras, instituições e idéias". Lua Nova. São Paulo: Cedec, n. 67. 
PMPA (PREFEITURA MUNICIPAL DE PORTO ALEGRE). 2001. Regimento interno do Orçamento Participativo.

SANTOS JUNIOR, 0. A.; AZEVEDO, S.; RIBEIRO, L. C. Q. 2004. "Democracia e gestão local: a experiência dos conselhos municipais no Brasil”. Rio de Janeiro: Revan.

SILVA, R. 1999. "Duas tensões na teoria democrática". Revista de Ciências Humanas. Florianópolis: UFSC (Edição Especial Temática), p. 41-59.

SORJ, B. 2005. Sociedades civis e relações Norte-Sul: ONGs e dependência. Centro Edelstein de Pesquisas Sociais. Working Paper 1, nov.

TATAGIBA, L. 2002. "Os Conselhos gestores e a democratização das políticas públicas no Brasil”. In: DAGNINO.E (Org.). Sociedade civil e espaços públicos no Brasil. Rio de Janeiro: Paz e Terra. p. 47-103.

; TEIXEIRA, A. C C. 2006. Democracia representativa e participativa:

complementaridade ou combinação subordinada? Reflexões sobre instituições participativas e gestão pública na cidade de São Paulo (2000-2004). XIX Concurso do Clad sobre Reforma do Estado e Modernização da Administração Pública. Guatemala.

TEIXEIRA, E. C. 1996. "Movimentos sociais e conselhos". Cadernos da Abong, n. 15 , p. $7-20$, julho.

VITULLO, G. 0. 2000. "Desafio da construção de um modelo democrático deliberativo". Revista Sociologias. Porto Alegre, ano 2, n. 3, p. 186-231, jan./jun.

URBINATI, N. 2006. "O que torna a representação democrática?" Lua Nova. São Paulo, n. 67.

YOUNG, I. M. 2006. "Representação política, identidade e minorias". Lua Nova. São Paulo, n. 67. 


\section{A REPRESENTAÇÃO NO INTERIOR DAS EXPERIÊNCIAS DE PARTICIPAÇÃO}

220 LÍGIA HELENA HAHN LÜCHMANN

O debate contemporâneo sobre a democracia vem desafiando o desenvolvimento de estudos e reflexões acerca das relações entre participação e representação no interior das práticas e experiências participativas. Tendo em vista que, de maneira geral, a participação ocorre por meio da representação, este trabalho objetiva analisar, tomando como referência algumas experiências participativas brasileiras (Conselhos Gestores e Orçamento Participativo), o fenômeno da representação no interior da participação (ou das práticas de participação e representação). Ancorado no pressuposto de que as reflexões teóricas sobre esses dois instrumentos de ação política - participação e representação - têm feito predominar um viés dualista que guarda separações dadas pelos diferentes modelos teóricos de democracia, o artigo analisa alguns fatores que parecem cooperar significativamente para esse dualismo, chamando a atenção para o fato de que as expe- 
riências participativas trazem à tona algumas especificidades na dinâmica da representação política. Os diferentes desenhos institucionais, ou as diferentes configurações entre participação e representação, bem como os diferentes tipos de políticas públicas são, entre outros, elementos centrais para o entendimento das diferentes dinâmicas de representação e participação entre os modelos empíricos analisados.

Palavras-chave: Participação; Representação; Democracia; Orçamento participativo; Conselhos gestores.

\section{REPRESENTATION WITHIN PARTICIPATIVE EXPERIENCES}

The contemporary debate on democracy challenges the development of studies and reflections about the links between participation and representation in the field of participative practices and experiences. Taking into account that generally participation occurs through representation, this article aims at analyzing some Brazilian participative experiences (decision-making councils and participatory budgeting), the phenomenon of representation within the process of participation (or within the participative and representative practices). Based on the supposition that the theoretical reflections about these two forms of political action - participation and representation - have been dominated by a dualist approach, related to different theoretical models of democracy, this article analyzes some factors which may contribute to that dualism.

Keywords: Participation; Representation; Democracy; Participatory budget; Decision-making councils 